\title{
Possible Gender-Related Modulation by the ROCK1 Gene in Colorectal Cancer Susceptibility
}

\author{
Cinzia Zucchini ${ }^{a}$ Marcella Martinellia Paola De Sanctis ${ }^{a} \quad$ Maria Teresa Rodia $^{a}$ \\ Gabriella Mattei $^{a} \quad$ Giampaolo Ugolini $^{b}$ Isacco Montroni ${ }^{b}$ Federico Ghignone ${ }^{b}$ \\ Rossella Solmia \\ Departments of a Experimental, Diagnostic and Specialty Medicine and ${ }^{\mathrm{b}}$ Medical and Surgical Sciences, University of \\ Bologna, Bologna, Italy
}

\section{Key Words}

ROCK1 $\cdot$ ROCK2 Colorectal cancer · Gene polymorphism · Association study

\begin{abstract}
Aim: In view of accumulating evidence supporting a pivotal role of the Rho/ROCK pathway in cancer, we investigated Rho-kinase polymorphisms as potential susceptibility factors in colorectal cancer (CRC) in a representative sample of the Italian population. Methods: DNA obtained from the peripheral blood samples of 137 CRC patients and 141 healthy controls was genotyped for four ROCK1 (rs35996865; rs73963110; rs2127958; rs288980) and five ROCK2 (rs12692437; rs7563468; rs35768389; rs17463896; rs16857265) selected single nucleotide polymorphisms. Results: None of the allelic variants of the nine selected markers was associated with the occurrence of $C R C$ or with the development of regional lymph node metastasis. By contrast, the ROCK1 rs35996865 G variant allele was significantly more frequent in male patients $(p=0.028)$ than in the control group. Conclusion: This finding is, at present, the first that points to a possible gender-related modulation by the ROCK1 gene in CRC susceptibility.
\end{abstract}

(C) 2015 S. Karger AG, Basel

$1015-2008 / 15 / 0826-0252 \$ 39.50 / 0$

\section{Introduction}

Every year, about 1 million people worldwide develop colorectal cancer (CRC). The majority of CRC cases occur in people who have no family risk factor, whereas 15$20 \%$ occur in people with a family history [1]. CRC is by far the most frequent tumor in the Italian population, with nearly 52,000 diagnoses estimated for 2014 by the Ministry of Health, based on data from the Italian Association of Medical Oncology (AIOM) and the Italian Association of Tumor Registration (ARTIUM).

Considering the great incidence of this pathology, many efforts have been made to elucidate the molecular bases of CRC etiology, but the causes still remain unclear. Several studies have been carried out in order to reveal the potential association between polymorphic genetic variants and the risk of CRC [2-5], although the actual genetic contribution to CRC is still not completely understood. In the challenge to establish the molecular basis of individual susceptibility and the factors that initiate the development of the tumor and its progression, ROCKs

C.Z. and M.M. contributed equally to this work as first authors.

\section{KARGER 125}

E-Mail karger@karger.com www.karger.com/pat
Marcella Martinelli, $\mathrm{PhD}$

Department of Experimental, Diagnostic and Specialty Medicine University of Bologna

via Belmeloro 8, IT-40126 Bologna (Italy)

E-Mail marcella.martinelli@ unibo.it 
deserve greater insight. ROCK1 and ROCK2, the main downstream effectors of the Rho family of GTPases, are serine-threonine kinases that act as central regulators of actin cytoskeleton dynamics. Through the phosphorylation of a range of target substrates involved in the cytoskeleton organization, such as myosin light chain (MLC) $[6,7]$, MLC phosphatase (MYPT1) $[8,9]$, ezrin/radixin/ moesin (ERM) [10], adducin [11] and LIM kinase (LIMK) [12], ROCKs control the formation of actin stress fibers, focal adhesions and cellular myosin-based contractility [13]. The two isoforms described, ROCK1 and ROCK2, although encoded by distinct genes, share $65 \%$ homology in their amino acid sequences [14]. Despite the extensive homology as well as their substrate promiscuity, the two ROCK isoforms have distinct functions. In particular, ROCK2 depletion has been reported to enhance microfilament bundle assembly into stress fibers and focal adhesion formation, whereas ROCK1-depleted cells show an opposite phenotype, and ROCK1 seems to be required for myosin II-dependent phagocytosis [15-17].

Since actin cytoskeleton dynamics mediate a number of cellular processes involved in the malignant phenotype gain, such as the regulation of morphology, cell-cell adhesion, migration and invasion, the implication of ROCK1 and ROCK2 in cancer is not surprising. Overexpression of ROCK has been described in many solid tumors, including hepatocellular carcinoma [18], osteosarcoma [19, 20], breast cancer [21], testicular cancer [22], bladder cancer [23] and also colon cancer [24]. In addition, several studies have emphasized the antimigratory and antiinvasive activity due to ROCK inhibition [25-28] or silencing $[18,24,29,30]$, reinforcing the association between the Rho-ROCK axis and cancer. Recently, Sari et al. [31] suggested that genetic polymorphisms in the ROCK1 and ROCK2 genes modify individual susceptibility to CRC in the Turkish population. Thus, in the present study we examined the genetic influence of Rho-kinase polymorphisms on CRC susceptibility in a representative sample of the Italian population.

\section{Materials and Methods}

\section{Sample Study}

A cohort of 137 unrelated Italian CRC patients was recruited by the Department of Medical and Surgical Sciences of S. OrsolaMalpighi Polyclinic, Bologna University. Diagnosis of CRC was confirmed by histopathological examination. The control group consisted of 141 unrelated healthy volunteers with matching ethnic origin and from the same geographical area (Italy).

The study was approved by the ethics committee of Sant'OrsolaMalpighi General Hospital and complied with the Helsinki Decla-
Table 1. Characteristics of CRC patients

\begin{tabular}{lc}
\hline Variable & Cancer cases, $\mathrm{n}(\%)$ \\
\hline Age & \\
$\quad<50$ years & $8(5.8)$ \\
$\geq 50$ years & $123(89.8)$ \\
NDA & $6(4.4)$ \\
\hline Sex & $72(52.6)$ \\
Male & $65(47.4)$ \\
Female & \\
Grading & $8(5.8)$ \\
G1 & $90(65.7)$ \\
G2 & $25(18.2)$ \\
G3 & $14(10.2)$ \\
NDA & $72(52.6)$ \\
\hline Lymph node metastasis & $42(30.7)$ \\
N0 & $23(16.8)$ \\
N1/2 & \\
NDA & $111(81)$ \\
\hline Family history & $14(10)$ \\
Negative & $12(8.8)$ \\
Positive & $79(57.7)$ \\
NDA & $16(11.7)$ \\
Smoking history & $31(22.6)$ \\
Never & $11(8)$ \\
Active smoker &
\end{tabular}

NDA $=$ No data available

ration's Ethical Principles for Medical Research Involving Human Subjects. Written informed consent was obtained from all patients and healthy control subjects before study entry. The patient characteristics are summarized in table 1. DNA extraction from peripheral whole blood, collected before primary surgery, was performed using the GenElute ${ }^{\mathrm{TM}}$ Blood Genomic DNA Kit (Sigma, Milan, Italy).

\section{Single Nucleotide Polymorphism Genotyping}

In order to investigate ROCK1 and ROCK2 genes we chose a total of nine single nucleotide polymorphisms (SNPs). Markers were selected using the HaploTagger tool for maximizing SNP prediction accuracy [32] as well as on the basis of literature data [31].

Table 2 summarizes the details of the investigated polymorphisms. It is noteworthy that the rs35768389 SNP mapping on the ROCK2 gene represents a missense variant (Val601Asp). Each polymorphism was amplified by PCR using flanking primers and the products were incubated with a specific restriction endonuclease (table 2). In a couple of primers a mismatch was inserted in order to create a restriction site for a common enzyme. Restriction fragments were separated by $10 \%$ native polyacrylamide gel electrophoresis and then stained with ethidium bromide. To assess the accuracy of the genotyping outputs, one third of the samples selected at random were blindly tested by a second operator. The DNA sample of 1 patient was used up when we genotyped the ROCK2 markers. 
Table 2. Details of the SNP investigation

\begin{tabular}{|c|c|c|c|c|c|c|}
\hline \multirow{2}{*}{$\begin{array}{l}\text { Gene and poly- } \\
\text { morphism ID } \\
\text { ROCK1 rs35996865 }\end{array}$} & \multicolumn{2}{|c|}{ SNP position ${ }^{1}$} & \multirow{2}{*}{$\begin{array}{l}\begin{array}{l}\text { Nucleotide } \\
\text { change }\end{array} \\
\mathrm{T}>\mathrm{G}\end{array}$} & \multirow{2}{*}{$\begin{array}{l}\text { Primer sequence }\left(5^{\prime}-3^{\prime}\right) \\
\text { Fw-TACCAGCATTGAGCACCAGT } \\
\text { Rev-TTGACTGTATCTTCCGGAGTCA }\end{array}$} & \multirow{2}{*}{$\begin{array}{l}\text { Amplimer, } \\
\text { bp } \\
189\end{array}$} & \multirow{2}{*}{$\begin{array}{l}\begin{array}{l}\text { Restriction } \\
\text { enzyme }\end{array} \\
\text { BstX I }\end{array}$} \\
\hline & $5^{\prime}$-UTR & chr18:21112383 & & & & \\
\hline ROCK1 rs73963110 & intron 1 & chr18:21098352 & $\mathrm{T}>\mathrm{C}$ & $\begin{array}{l}\text { Fw-AGTGGCATTGTCAACCAACA } \\
\text { Rev-TTTCCCCTATGTCCAGATCA }\end{array}$ & 212 & Fnu4H I \\
\hline ROCK1 rs2127958 & intron 1 & chr18:21073648 & $\mathrm{C}>\mathrm{T}$ & $\begin{array}{l}\text { Fw-GAGTCAGGTGTAAAACATCATTTAGG } \\
\text { Rev-GGGTGGTGTTTCTCCAAAAAT }\end{array}$ & 190 & Dra I \\
\hline ROCK2 rs12692437 & intron 1 & chr2:11340435 & $\mathrm{T}>\mathrm{C}$ & $\begin{array}{l}\text { Fw-CTTCACATCAACAGTAAGgTCCA }{ }^{2} \\
\text { Rev-TTCTTTATGAAGAGTTTGGCATTT }\end{array}$ & 151 & Hpy166 II \\
\hline ROCK2 rs7563468 & intron 1 & chr2:11291149 & $\mathrm{G}>\mathrm{A}$ & $\begin{array}{l}\text { Fw-AGCCAAACACCCAGTTTCC } \\
\text { Rev-CACCTGGCCAACAACAATAA }\end{array}$ & 192 & Dpn II \\
\hline ROCK2 rs35768389 & exon 16 & chr2:11214974 & $\mathrm{T}>\mathrm{A}$ & $\begin{array}{l}\text { Fw-TAACTTGGCAGTCTCCAGCA } \\
\text { Rev-TGTTGTTTGGTTTTGAATGGA }\end{array}$ & 181 & Dpn II \\
\hline
\end{tabular}

${ }^{1}$ UCSC Genome Browser assembly ID: hg38. ${ }^{2}$ Insertion of mutation T>G. ${ }^{3}$ Insertion of mutation A $>$ C.

\section{Statistical Analysis}

The distribution of genotypes in the patient and control groups was tested for deviation from the Hardy-Weinberg equilibrium (HWE) using Pearson's $\chi^{2}$ test. A borderline disequilibrium ( $\mathrm{p}=$ 0.045) was noted for the rs35996865 SNP in the control group. Since the deviation from HWE was marginally significant, we did not exclude that particular SNP from the investigation. Genetic association was firstly investigated using a likelihood ratio approach by Unphased software v3.1.5 for Windows Vista [33]. Odds ratios were calculated in order to estimate the level of association of the rare allele carriers, i.e. heterozygotes versus noncarriers, as well as homozygotes versus noncarriers.

Linkage disequilibrium between SNPs was calculated using the Haploview program. Haplotype association analysis was performed to further investigate the association between CRC and ROCK1 or ROCK2 polymorphisms. The haplotype association analysis was performed with the aid of Unphased software. A specific test for each haplotype was carried out. This test is a score test for a difference in risk between one haplotype and all the others pooled together. This is in contrast with the odds ratios, which were calculated in relation to a single reference haplotype. A permutation test was performed with 10,000 sample replicates to allow for multiple testing corrections over all the performed tests. In each replicate the trait values were randomly shuffled between all subjects.

\section{Results}

Only a single genotype was missing in the genotyping step (call rate $>99.9 \%$ ). The assay for the ROCK1 polymorphism rs73963110 did not provide any evidence of variant alleles in our data set; therefore, the SNP was excluded from the statistical analysis. A case-control association study was performed in order to test whether genetic variants in ROCK1 or ROCK2 genes were associated with CRC as a whole, with CRC in a specific gender, or with the occurrence of lymph node metastasis (tables $3,4)$. Variant alleles appeared not to be associated with the occurrence of CRC or with regional lymph node metastasis for any of the investigated genes; however, a significant association was observed with CRC occurrence in males. Indeed, the variant allele of the rs35996865 mapping in ROCK1 was more frequent in male patients $(\mathrm{p}=0.028)$ than in the control group. The calculated odds ratio (OR) for rs35996865 variant allele $(G)$ heterozygote carriers versus noncarriers (ORhet) was 1.88 (95\% CI 1.02-3.49), while for homozygote carriers versus noncarriers (ORhom) it was not significant (OR 1.977, 95\% CI 0.76-5.13), probably due to the small number of individuals with that genotype. However, considering the genotypes presenting the variant together, the OR was 1.9 (95\% CI 1.07-3.38). The variant allele was more frequent in male patients (minor allele frequency, MAF = 0.33 ) with respect to controls $(\mathrm{MAF}=0.23)$, while the female patient frequency (MAF $=0.23$ ) was close to controls. No difference in allelic frequency was observed between genders within the control group $(\mathrm{p}=0.45)$. To further investigate the genetic association between 
Table 3. Association analysis of ROCK1 locus

\begin{tabular}{|c|c|c|c|c|c|c|c|c|c|}
\hline \multicolumn{2}{|c|}{ SNP information } & \multirow[t]{2}{*}{ Sample } & \multicolumn{3}{|c|}{ Genotype, $\mathrm{n}$} & \multirow[t]{2}{*}{ MAF } & \multirow[t]{2}{*}{$\mathrm{p}$ value } & \multicolumn{2}{|l|}{ Relative risk (95\% CI) } \\
\hline SNP ID & alleles $^{1}$ & & 11 & 12 & 22 & & & $\mathrm{OR}_{\text {het }}$ & $\mathrm{OR}_{\mathrm{hom}}$ \\
\hline \multirow[t]{6}{*}{ rs35996865 } & \multirow[t]{6}{*}{$\mathrm{T} / \mathrm{G}$} & Control & 87 & 42 & 12 & 0.23 & ref. & ref. & ref. \\
\hline & & Case & 71 & 54 & 12 & 0.28 & 0.173 & $1.575(0.945-2.626)$ & $1.225(0.519-2.894)$ \\
\hline & & Case male & 33 & 30 & 9 & 0.33 & 0.0285 & $1.883(1.017-3.488)$ & $1.977(0.763-5.126)$ \\
\hline & & Case female & 38 & 24 & 3 & 0.23 & 0.9418 & $1.308(0.697-2.456)$ & $0.572(0.153-2.145)$ \\
\hline & & Case N0 & 37 & 29 & 5 & 0.27 & 0.3606 & $1.624(0.882-2.988)$ & $0.98(0.322-2.979)$ \\
\hline & & Case N1/2 & 20 & 16 & 6 & 0.33 & 0.0675 & $1.657(0.78-3.521)$ & $2.175(0.728-6.494)$ \\
\hline \multirow[t]{6}{*}{ rs2127958 } & \multirow[t]{6}{*}{$\mathrm{C} / \mathrm{T}$} & Control & 22 & 72 & 47 & 0.41 & ref. & ref. & ref. \\
\hline & & Case & 22 & 56 & 59 & 0.36 & 0.2619 & $0.778(0.392-1.545)$ & $1.255(0.621-2.539)$ \\
\hline & & Case male & 11 & 30 & 31 & 0.36 & 0.3156 & $0.833(0.360-1.930)$ & $1.319(0.562-3.099)$ \\
\hline & & Case female & 11 & 26 & 28 & 0.37 & 0.417 & $0.722(0.308-1.692)$ & $1.191(0.503-2.821)$ \\
\hline & & Case N0 & 11 & 29 & 32 & 0.35 & 0.2528 & $0.806(0.347-1.870)$ & $1.362(0.581-3.192)$ \\
\hline & & Case N1/2 & 8 & 16 & 17 & 0.39 & 0.732 & $0.611(0.231-1.618)$ & $0.995(0.373-2.653)$ \\
\hline \multirow[t]{6}{*}{ rs288980 } & \multirow[t]{6}{*}{$\mathrm{C} / \mathrm{T}$} & Control & 40 & 72 & 29 & 0.46 & ref. & ref. & ref. \\
\hline & & Case & 38 & 66 & 33 & 0.48 & 0.6239 & $0.965(0.554-1.682)$ & $1.198(0.614-2.336)$ \\
\hline & & Case male & 17 & 38 & 17 & 0.5 & 0.4456 & $1.242(0.623-2.476)$ & $1.379(0.605-3.147)$ \\
\hline & & Case female & 21 & 28 & 16 & 0.46 & 0.9918 & $0.741(0.373-1.470)$ & $1.051(0.469-2.356)$ \\
\hline & & Case N0 & 22 & 34 & 15 & 0.45 & 0.8409 & $0.859(0.443-1.663)$ & $0.94(0.418-2.118)$ \\
\hline & & Case N1/2 & 12 & 17 & 13 & 0.51 & 0.412 & $0.787(0.342-1.812)$ & $1.494(0.596-3.745)$ \\
\hline
\end{tabular}

$\mathrm{p}$ values are for association analysis. N0 = Tumor cells absent from regional lymph nodes; N1/2 = regional lymph node metastasis present. ${ }^{1}$ Ancestral allele first (in NCBI dbSNP database).

ROCK1 or ROCK2 and CRC, a haplotype association analysis was performed. No haplotype showed a higher level of association than alleles or among sex strata (data not shown).

\section{Discussion}

Given the wide spectrum of actin cytoskeleton activities influenced by ROCKs, it is not surprising that the expression and activity of these kinases in CRC has been extensively explored. Sari et al. [31] showed that protein expression of both ROCK1 and ROCK2 was markedly augmented in CRC patients. In addition, it has been demonstrated that the inhibition of ROCKs by Y-27632, a compound that simultaneously targets the two kinase isoforms, significantly reduced the motility of colon adenocarcinoma cells [27] and that ROCK2 knockdown decreased invasiveness in highly malignant intestinal epithelial cell lines [24]. Conversely, several reports showed that the inhibition of Rho-kinase stimulates colon cancer cell proliferation, progression and migration [34-36]. Thus, the precise contribution of ROCK kinase to CRC progression and invasion remains controversial and needs more clarification.

ROCK1 Involvement in CRC Male Patients
Very little is known about the relationship between ROCK1 and ROCK2 genetic variants and the susceptibility to CRC and, at present, only one other group has investigated a possible association between ROCK1 and ROCK2 polymorphisms and the risk of CRC [31]. For the present study, we genotyped a total of nine SNPs: four of them mapping on ROCK1 gene and the remaining five on ROCK2, in order to explore the possible involvement of these two kinases in colorectal carcinogenesis in a subset of the Italian population.

None of the nine selected polymorphisms showed significant allele or genotype association with the occurrence of CRC, suggesting that these SNPs are not directly involved in CRC onset in the studied population. It is noteworthy that no evidence of an association was found for ROCK2 rs35768389 or for ROCK1 rs73963110 variants, which have been previously described as relevant to CRC development in a Turkish cohort [31]. Specifically, in our study no statistically significant difference was found in genotype and allele frequencies for the rs35768389 polymorphism between the control and patient groups, whereas the genotyping of the ROCK1 polymorphism rs73963110 did not provide any evidence of a variant allele in our entire data set. These conflicting re- 
Table 4. Association analysis of ROCK2 locus

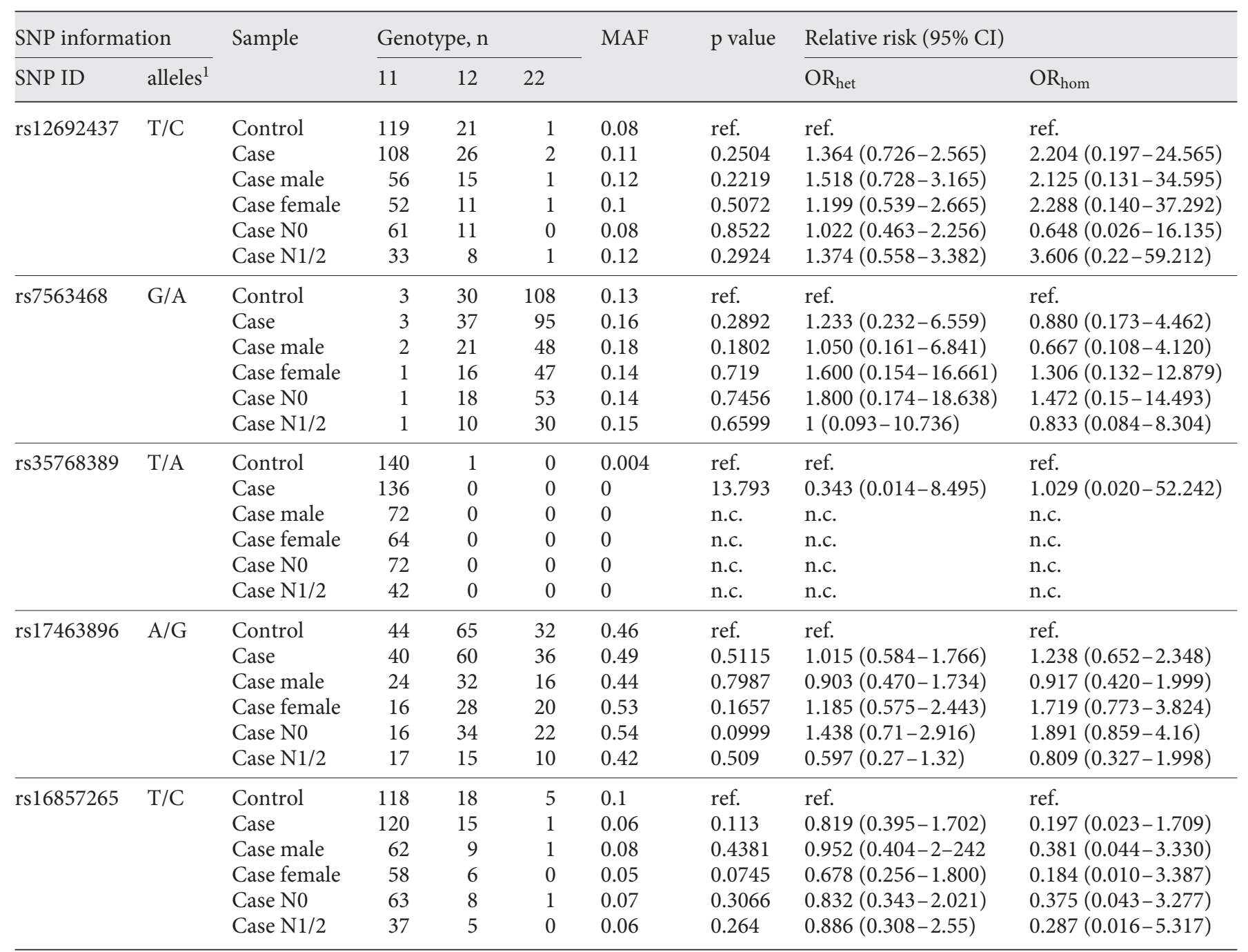

$\mathrm{p}$ values are for association analysis. N0 = Tumor cells absent from regional lymph nodes; N1/2 = regional lymph node metastasis present; n.c. $=$ not calculable. ${ }^{1}$ Ancestral allele first (in NCBI dbSNP database).

sults could be justified considering first that the influence of genetic factors on colon cancer disease may significantly differ among populations with various origins. The discrepancy may also depend on the different allelic frequencies observed for the two studied groups. Notably, the allele frequency for the above-mentioned markers in the Italian cohort reaches values more consistent with the NCBI database than with the Turkish ones.

When a case-control association study was performed in order to assess the association of the selected genetic variants in ROCK1 or ROCK2 genes with CRC in a specific gender, we found that the variant allele of the rs35996865 SNP mapping in ROCK1 was more frequent in male patients $(\mathrm{p}=0.028)$ than in the control group. To our knowledge, this represents the first evidence of a possible correlation between polymorphic genetic variants of ROCK1 and the increased risk in CRC male patients. The risk of CRC shows sexual dimorphism, with a significantly higher incidence rate in males than in females (2:1) [37]. It has been proposed that male hormones play a key role in the development of colonic adenomas [38]. Moreover, several reports describe a link between androgens and the ROCK signaling pathway [39-41]. On the other hand, cytokines have been associated with the diffusion of human cancer cells of an epithelial origin and, in particular, IL-6 was observed to induce gastric cancer pro- 
gression via activation of the c-Src/RhoA/ROCK signaling pathway [42]. Notably, estrogens inhibit IL-6 production and the lower concentration of this hormone in males seems to justify the disparity of occurrence of hepatocellular carcinoma in males compared to females [43]. In the light of these considerations, we propose that this relationship between sexual hormones and RhoA/ ROCK signaling may be influenced by gender-dependent differences in ROCK1 gene expression control. Remarkably, the ROCK1 rs35996865 G variant we found associated with CRC in males maps on $5^{\prime}$-UTR, a putative regulatory region that could be influenced by a different upstream modulation, depending on gender. As a last consideration, the rs35996865 polymorphism was recently associated with the risk of developing metabolic syndrome in a Turkish population [44] and clear cell renal cell carcinoma in a Chinese population [45]. Data about this SNP in the literature are rare, so it is impressive that it could play a role in both obesity, a risk factor for CRC, and in another type of carcinoma.

Taking into account the involvement of ROCK isoforms in invasiveness, we analyzed the relationship between the selected polymorphisms and the presence of regional lymph node metastasis. Despite ROCKs being attractive candidate genes, our allelic association study did not support the selected variants in ROCK1 and ROCK2 having an effect on colon cancer lymph node diffusion. However, considering the pivotal role played by ROCK1 and 2 in migration [46], caution should be adopted in completely ruling out their biological role in CRC invasiveness, and we believe that further investigation in patients presenting metastasis in distal organs could help to better clarify the real involvement of ROCK polymorphisms in influencing the invasive and metastatic properties of CRC cells.

These overall results suggest a potential minor role for Rho-kinase polymorphisms in CRC development in the Italian population, limited to the male subgroup of patients. It should be considered that although the selected markers tag the large majority of polymorphisms presenting an MAF $>0.05$, the degree of information provided for rarer polymorphisms is very low. Therefore, the absence of an association with CRC for our whole sample does not necessarily rule out a role for ROCK1 or 2 in CRC etiology, since other untyped rare polymorphisms could represent susceptibility factors. In addition, two of the genotyped SNPs, selected because they were previously seen to be involved in a predisposition for CRC [31], were not polymorphic in our sample study, rendering them no longer informative to us. Moreover, it is helpful to recall that ROCK1 and ROCK2 are central players in the cytoskeleton remodeling pathway, a complex genetic network that includes a large number of ROCKs upstream [47]. It is likely that the effect of such a limited number of SNPs could be masked by the relationship among ROCKs and their numerous specific interaction partners. Therefore, further explorations both in the genetic and the epigenetic field are advisable in order to investigate the key role of Rho-kinases in CRC occurrence in greater detail.

\section{Acknowledgments}

This study was supported by grants from the Fondazione Enzo Piccinini (Modena, Italy) and by grants from the Fondazione del Monte (Bologna and Ravenna, Italy, to M.M. and R.S.).

\section{References}

1 Cunningham D, Atkin W, Lenz HJ, Lynch HT, Minsky B, Nordlinger B, Starling N: Colorectal cancer. Lancet 2010;375:1030-1047.

2 Nassiri M, Kooshyar MM, Roudbar Z, Mahdavi M, Doosti M: Genes and SNPs associated with non-hereditary and hereditary colorectal cancer. Asian Pac J Cancer Prev 2013;14: 5609-5614.

3 Mimori K, Tanaka F, Shibata K, Mori M: Review: single nucleotide polymorphisms associated with the oncogenesis of colorectal cancer. Surg Today 2012;42:215-219.

4 Martinelli M, Ugolini G, Scapoli L, Rivetti S, Lauriola M, Mattei G, Rosati G, Montroni I, Manaresi A, Zattoni D, Taffurelli M, Solmi R: The EGFR R521K polymorphism influences the risk to develop colorectal cancer. Cancer Biomark 2010;8:61-65.
5 Martinelli M, Scapoli L, Cura F, Rodia MT, Ugolini G, Montroni I, Solmi R: Colorectal cancer susceptibility: apparent gender-related modulation by $\mathrm{ABCB} 1$ gene polymorphisms. J Biomed Sci 2014;21:89.

6 Amano M, Ito M, Kimura K, Fukata Y, Chihara K, Nakano T, Matsuura Y, Kaibuchi K: Phosphorylation and activation of myosin by Rho-associated kinase (Rho-kinase). J Biol Chem 1996;271:20246-20249.

7 Kureishi Y, Kobayashi S, Amano M, Kimura K, Kanaide H, Nakano T, Kaibuchi K, Ito M: Rho-associated kinase directly induces smooth muscle contraction through myosin light chain phosphorylation. J Biol Chem 1997;272:12257-12260.
8 Kawano Y, Fukata Y, Oshiro N, Amano M, Nakamura T, Ito M, Matsumura F, Inagaki M, Kaibuchi K: Phosphorylation of myosinbinding subunit (Mbs) of myosin phosphatase by Rho-kinase in vivo. J Cell Biol 1999; 147:1023-1038.

9 Kimura K, Ito M, Amano M, Chihara K, Fukata Y, Nakafuku M, Yamamori B, Feng J, Nakano T, Okawa K, Iwamatsu A, Kaibuchi K: Regulation of myosin phosphatase by Rho and Rho-associated kinase (Rho-kinase). Science 1996;273:245-248.

10 Matsui T, Maeda M, Doi Y, Yonemura S, Amano M, Kaibuchi K, Tsukita S, Tsukita S: Rho-kinase phosphorylates $\mathrm{COOH}$-terminal threonines of ezrin/radixin/moesin (ERM) proteins and regulates their head-to-tail association. J Cell Biol 1998;140:647-657.
ROCK1 Involvement in CRC Male Patients
Pathobiology 2015;82:252-258

DOI: $10.1159 / 000439405$ 
11 Fukata Y, Oshiro N, Kinoshita N, Kawano Y, Matsuoka Y, Bennett V, Matsuura Y, Kaibuchi K: Phosphorylation of adducin by Rhokinase plays a crucial role in cell motility. J Cell Biol 1999;145:347-361.

12 Maekawa M, Ishizaki T, Boku S, Watanabe N, Fujita A, Iwamatsu A, Obinata T, Ohashi K, Mizuno K, Narumiya S: Signaling from Rho to the actin cytoskeleton through protein kinases ROCK and LIM-kinase. Science 1999; 285:895-898.

13 Riento K, Ridley AJ: ROCKs: multifunctional kinases in cell behaviour. Nat Rev Mol Cell Biol 2003;4:446-456.

14 Nakagawa O, Fujisawa K, Ishizaki T, Saito Y, Nakao K, Narumiya S: ROCK-I and ROCKII, two isoforms of Rho-associated coiled-coil forming protein serine/threonine kinase in mice. FEBS Lett 1996;392:189-193.

15 Yoneda A, Multhaupt HA, Couchman JR: The Rho kinases I and II regulate different aspects of myosin ii activity. J Cell Biol 2005; 170:443-453.

16 Yoneda A, Ushakov D, Multhaupt HA, Couchman JR: Fibronectin matrix assembly requires distinct contributions from Rho kinases I and II. Mol Biol Cell 2007;18:66-75.

17 Lock FE, Ryan KR, Poulter NS, Parsons M, Hotchin NA: Differential regulation of adhesion complex turnover by ROCK1 and ROCK2. PloS One 2012;7:e31423.

18 Wong CC, Wong CM, Tung EK, Man K, Ng IO: Rho-kinase 2 is frequently overexpressed in hepatocellular carcinoma and involved in tumor invasion. Hepatology 2009;49:1583-1594.

19 Liu X, Choy E, Hornicek FJ, Yang S, Yang C, Harmon D, Mankin H, Duan Z: ROCK1 as a potential therapeutic target in osteosarcoma. J Orthop Res 2011;29:1259-1266.

20 Zucchini C, Manara MC, Pinca RS, De Sanctis P, Guerzoni C, Sciandra M, Lollini PL, Cenacchi G, Picci P, Valvassori L, Scotlandi K: CD99 suppresses osteosarcoma cell migration through inhibition of ROCK2 activity. Oncogene 2014;33:1912-1921.

21 Lane J, Martin TA, Watkins G, Mansel RE, Jiang WG: The expression and prognostic value of ROCK I and ROCK II and their role in human breast cancer. Int J Oncol 2008;33: 585-593.

22 Kamai T, Yamanishi T, Shirataki H, Takagi K, Asami H, Ito Y, Yoshida K: Overexpression of Rhoa, Rac1, and Cdc42 GTPases is associated with progression in testicular cancer. Clin Cancer Res 2004;10:4799-4805.

23 Kamai T, Tsujii T, Arai K, Takagi K, Asami H, Ito Y, Oshima $\mathrm{H}$ : Significant association of Rho/ROCK pathway with invasion and metastasis of bladder cancer. Clin Cancer Res 2003;9:2632-2641.
24 Vishnubhotla R, Sun S, Huq J, Bulic M, Ramesh A, Guzman G, Cho M, Glover SC: ROCK-II mediates colon cancer invasion via regulation of MMP-2 and MMP-13 at the site of invadopodia as revealed by multiphoton imaging. Lab Invest 2007;87:1149-1158.

25 Nakajima M, Hayashi K, Egi Y, Katayama K, Amano Y, Uehata M, Ohtsuki M, Fujii A, Oshita K, Kataoka H, Chiba K, Goto N, Kondo T: Effect of Wf-536, a novel ROCK inhibitor, against metastasis of B16 melanoma. Cancer Chemother Pharmacol 2003;52:319-324.

26 Itoh $\mathrm{K}$, Yoshioka K, Akedo $\mathrm{H}$, Uehata $\mathrm{M}$, Ishizaki T, Narumiya S: An essential part for Rho-associated kinase in the transcellular invasion of tumor cells. Nat Med 1999;5:221225.

27 Paduch R, Kandefer-Szerszen M, SzusterCiesielska A, Plewka K: Transforming growth factor-beta 1 modulates metalloproteinase-2 and -9 , nitric oxide, RhoA and alpha-smooth muscle actin expression in colon adenocarcinoma cells. Cell Biol Int 2010;34:213-223.

28 Takamura M, Sakamoto M, Genda T, Ichida $\mathrm{T}$, Asakura H, Hirohashi S: Inhibition of intrahepatic metastasis of human hepatocellular carcinoma by Rho-associated protein kinase inhibitor Y-27632. Hepatology 2001;33: 577-581.

29 Patel RA, Liu Y, Wang B, Li R, Sebti SM: Identification of novel ROCK inhibitors with antimigratory and anti-invasive activities. Oncogene 2014;33:550-555.

30 Zhang C, Zhang S, Zhang Z, He J, Xu Y, Liu $S$ : ROCK has a crucial role in regulating prostate tumor growth through interaction with c-Myc. Oncogene 2014;33:5582-5591.

31 Sari I, Berberoglu B, Ozkara E, Oztuzcu S, Camci C, Demiryurek AT: Role of Rho-kinase gene polymorphisms and protein expressions in colorectal cancer development. Pathobiology 2013;80:138-145.

32 de Bakker PI, Yelensky R, Pe'er I, Gabriel SB, Daly MJ, Altshuler D: Efficiency and power in genetic association studies. Nat Genet 2005; 37:1217-1223.

33 Dudbridge F: Likelihood-based association analysis for nuclear families and unrelated subjects with missing genotype data. Hum Hered 2008;66:87-98.

34 Adachi S, Yasuda I, Nakashima M, Yamauchi T, Yoshioka T, Okano Y, Moriwaki H, Kozawa O: Rho-kinase inhibitor upregulates migration by altering focal adhesion formation via the Akt pathway in colon cancer cells. Eur J Pharmacol 2011;650:145-150.

35 Nakashima M, Adachi S, Yasuda I, Yamauchi $\mathrm{T}$, Kozawa O, Moriwaki H: Rho-kinase regulates negatively the epidermal growth factorstimulated colon cancer cell proliferation. Int J Oncol 2010;36:585-592.

36 Makrodouli E, Oikonomou E, Koc M, Andera L, Sasazuki T, Shirasawa S, Pintzas A: BRAF and RAS oncogenes regulate Rho GTPase pathways to mediate migration and invasion properties in human colon cancer cells: a comparative study. Mol Cancer 2011;10:118.
37 Abotchie PN, Vernon SW, Du XL: Gender differences in colorectal cancer incidence in the United States, 1975-2006. J Womens Health 2012;21:393-400.

38 Amos-Landgraf JM, Heijmans J, Wielenga MC, Dunkin E, Krentz KJ, Clipson L, Ederveen AG, Groothuis PG, Mosselman S, Muncan V, Hommes DW, Shedlovsky A, Dove WF, van den Brink GR: Sex disparity in colonic adenomagenesis involves promotion by male hormones, not protection by female hormones. Proc Natl Acad Sci USA 2014;111: 16514-16519.

39 Gonzalez-Montelongo MC, Marin R, Gomez T, Diaz M: Androgens differentially potentiate mouse intestinal smooth muscle by nongenomic activation of polyamine synthesis and Rho kinase activation. Endocrinology 2006;147:5715-5729.

40 Song J, Kost CK Jr, Martin DS: Androgens potentiate renal vascular responses to angiotensin II via amplification of the Rho kinase signaling pathway. Cardiovasc Res 2006;72:456463

41 Vignozzi L, Morelli A, Filippi S, Ambrosini S, Mancina R, Luconi M, Mungai S, Vannelli GB, Zhang XH, Forti G, Maggi M: Testosterone regulates RhoA/Rho-kinase signaling in two distinct animal models of chemical diabetes. J Sex Med 2007;4:620-630; discussion 631-632.

42 Lin MT, Lin BR, Chang CC, Chu CY, Su HJ, Chen ST, Jeng YM, Kuo ML: IL-6 induces AGS gastric cancer cell invasion via activation of the c-Src/RhoA/ROCK signaling pathway. Int J Cancer 2007;120:2600-2608.

43 Naugler WE, Sakurai T, Kim S, Maeda S, Kim K, Elsharkawy AM, Karin M: Gender disparity in liver cancer due to sex differences in MyD88-dependent IL-6 production. Science 2007;317:121-124.

44 Tabur S, Oztuzcu S, Oguz E, Korkmaz H, Eroglu S, Ozkaya M, Demiryurek AT: Association of Rho/Rho-kinase gene polymorphisms and expressions with obesity-related metabolic syndrome. Eur Rev Med Pharmacol Sci 2015;19:1680-1688.

45 Zhao R, Liu K, Huang Z, Wang J, Pan Y, Huang Y, Deng X, Liu J, Qin C, Cheng G, Hua L, Li J, Yin C: Genetic variants in caveolin-1 and RhoA/ROCK1 are associated with clear cell renal cell carcinoma risk in a Chinese population. PloS One 2015;10:e128771.

46 Kale VP, Hengst JA, Desai DH, Amin SG, Yun JK: The regulatory roles of ROCK and MRCK kinases in the plasticity of cancer cell migration. Cancer Lett 2015;361:185-196.

47 Morgan-Fisher M, Wewer UM, Yoneda A: Regulation of ROCK activity in cancer. J Histochem Cytochem 2013;61:185-198. 